\title{
TO STUDY THE RISK OF CARDIOVASCULAR MORBIDITY \& MORTALITY IN STABLE COPD PATIENTS
}

\author{
Ravi Dosi, B. Vijaya Bhaskar, G. K. Paramjyothi
}

1. Assistant Professor. Department of TB \& Chest diseases, SAIMS Medical College \& PG Institute, Indore.

2. EX HOD, Department of Pulmonary Medicine \& Critical Care, Mediciti Hospitals, In charge Pulmonology, Deccan Hospital, Hyderabad.

3. EX Professor, Department of Pulmonary Medicine \& Critical Care, Mediciti Hospitals, Professor Pulmonology, Nizam Institute of Medical Sciences, Hyderabad.

\section{CORRESPONDING AUTHOR}

Dr. Ravi Dosi,

Assistant Professor,

Department of TB \& Chest Diseases,

SAIMS, 124, Tilak Nagar main, Indore [MP],

E-mail: ravi.dosi@gmail.com

Ph: 00917869036808

ABSTRACT: The epidemiologic evidence linking COPD and cardiovascular morbidity and mortality is strong. Even after adjustments for traditional cardiovascular risk factors such as serum total cholesterol Hypertension, obesity and smoking, patients with COPD have a two- to threefold increase in the Risk of cardiovascular events including death. We concluded that more severe the stage of COPD more is the risk of cardiovascular morbidity \& mortality. Stable COPD patients are 1.5 [males] \& 1.4 [females] times at risk to develop cardiovascular disease as compared to the general population. Among the established risk factors studied: - Age > $60 \mathrm{yrs}$, Positive Smoking History, Left Ventricular Hypertrophy, and Body Mass Index > $30 \mathrm{Kg} / \mathrm{M} 2$ are found in a statistical significant correlation with progressively worsening stages of COPD.A positive but statistically insignificant correlation was demonstrable between the family history of cardiovascular disease in first degree relatives of Stable COPD patients, and increasing cardiovascular morbidity \& mortality. In stable COPD patients, Systemic hypertension with resultant Left ventricular Hypertrophy predisposes the patient to an increased risk of Myocardial infarction \& correspondingly increased CVS morbidity \& mortality. Progressively decreasing FEV1, decreasing FVC, decreasing FEV1/FVC ratio, have a statistically significant correlation to cardiovascular mortality \& morbidity. Se CRP levels provide an accurate indicator for assessment of severity of cardiovascular morbidity \& mortality in Stable COPD patients. Significant correlations were demonstrated between the treatment that patient requires for stability \& cardiovascular disease. Patients on Home Oxygen therapy, oral steroids \& bronchodilators despite being Stable COPD should be under closer surveillance for cardiovascular complications. Cardiovascular disease is an important but underrated cause of COPD morbidity \& mortality .Hence should be addressed to improve overall disease outcome.

INTRODUCTION: Chronic obstructive pulmonary disease (COPD) is a heterogeneous collection of conditions characterized by persistent expiratory airflow limitation. It can result from several etiologies, most importantly cigarette smoke, which can affect the lung by several distinct mechanisms. COPD affects approximately 5 per cent of adults in India. It is more common among men than women. It is difficult to assess its prevalence accurately as the symptoms are common to other well-known diseases such as asthma and TB. Surveys done by the Indian Council of 
Medical Research in 2006 among residents of Chandigarh, Delhi, Bangalore and Kanpur reflect that the prevalence is increasing, largely due to an increase in smoking and air pollution in rapidly urbanizing \& developing societies. Its incidence was expected to double in the world between 1990 and 2020, according to the Global Initiative for Obstructive Lung Disease (GOLD). By 2020, COPD is expected to become the third major cause of death. The cost of COPD to the country as well as to the individual is enormous. [2,3]. The prevalence rates in male subjects of $2.12 \%$ to $9.4 \%$ in studies reported from North India are generally higher than $1.4 \%$ to $4.08 \%$ reported from South India. The respective ranges for female subjects vary from $1.33 \%$ to $4.9 \%$ from North and from $2.55 \%$ to $2.7 \%$ from South India. For epidemiological assessment, the rounded-off median prevalence rates were assessed as $5 \%$ for male and $2.7 \%$ for female subjects of over 30 years of age. [4] COPD is a growing health burden worldwide, previously it was believed that most patients with COPD died from respiratory failure; however, emerging epidemiological data indicate that many COPD patients develop cardiovascular complications and die from cardiovascular causes of mortality.

COPD is an important risk factor for other causes of morbidity and mortality, including cardiovascular disorders [20,21]. Various population-based studies suggest that, independent of smoking, age and sex, COPD increases the risk of cardiovascular morbidity and mortality two-fold. Relatively small reductions in lung function increase the risk for ventricular arrhythmias, coronary events and cardiovascular mortality by two-fold, independent of the effects of smoking $[19,21$, and 22]. Among those with established COPD, the leading cause of hospitalization and mortality is related to the cardiovascular system, accounting for $40-50 \%$ of all hospitalizations and for $30-50 \%$ of all deaths among COPD patients [20,21]. A 10\% decrease in FEV1 among COPD patients increases the cardiovascular event rate by approximately $30 \%$ [21].

AIM: To study the risk of Cardiovascular Morbidity \& Mortality in Stable COPD patients based on established cardiovascular risk factors .

\section{OBJECTIVES:}

1. To estimate the incidence of cardiovascular mortality in Stable COPD patients.

2. To estimate the incidence of cardiovascular morbidity in Stable COPD patients.

3. To calculate the incidence of cardiovascular risk factors [established by Framingham Heart Study] in Stable COPD patients.

4. To determine the strength of association in between the increasing severity of COPD \& incidence of the risk factors.

5. To assess if treatment given to COPD patients has an association with the cardiovascular morbidity \& mortality.

6. To compare the strength of association in between the risk factors and increasing severity of

COPD: MATERIALS \& METHODS: The present study entitled "To Study The Risk Of Cardiovascular Morbidity \& Mortality In Stable COPD Patients Based On Established Cardiovascular Risk Factors" was undertaken at Mediciti Hospitals, Hyderabad, a tertiary care referral center.

METHODOLOGY: Study Design: An Institutional based case control study. Study Setting: Department of Pulmonary Medicine, Mediciti Hospitals, Hyderabad. Study Period: Two years extending from Dec 2007 to Dec 2009. 
INCLUSION CRITERIA: A] CASE COPD was diagnosed by premorbid pulmonary function testing when available. In the absence of documented airflow obstruction we used clinical criteria, clinical history with compatible physical findings and/or evidence of hyperinflation on chest radiograph in support of the diagnosis of COPD as described in 1987 statement from American Thoracic Society $(1,3$, and 5$)$.

In patients with COPD, acute exacerbation was diagnosed if the following criteria $(\mathbf{1}, \mathbf{3})$ were present:

(i) Recent rapid worsening of dyspnoea (ii) Increase in sputum purulence; and

(iii) Increase in sputum volume

B] CONTROL Patients referred to dept of pulmonary medicine for pre operative Pulmonology clearance with no known established or past history of chronic respiratory illness.

\section{Exclusion Criteria:}

1. Patients with primary pathology like bronchial asthma, bronchiectasis and restrictive lung disease like kyphoscoliosis.

2. Patients with established history of Rheumatic, Congenital, Ischemic heart disease, Valvular heart diseases, coronary artery disease and chronic liver \& kidneys diseases.

3. Patients with pre-existing structural lung diseases, lung cancer \& critically ill, active pulmonary Koch?s and established

4. Immunosuppressive patients [ HIV positivity, malignant diseases, organ transplant patients, on chemotherapy ]

5. Patients on prolonged statin therapy

6. Patients presenting with infective exacerbations, frank purulent expectoration

7. History of pneumonic illness in past 1 month

8. Patients older than 75 yrs of age.

Data Collection: A total of 200 COPD cases attending Mediciti Hospital Pulmonology OPD and Emergency room. were screened from which 100 patients were selected randomly, studied clinically, lipid profile analysis, CRP, electrocardiographically, pulmonary function test. Patients were investigated when their condition stabilized, before they were discharged, after obtaining informed consent.

A detailed history was taken in all patients, particularly focused on symptoms related to respiratory system, smoking, environmental exposure, presence or absence of co-morbid factors

PACK YEAR was computed in cigarette smokers from the average number of cigarettes smoked per day, one pack year being smoking of 20 cigarettes per day for one year. "Cigarette equivalent pack years" were computed. This was arrived at by dividing the "Pack years" calculated on the basis of smoking beedis by four. Active smoking status was defined as having smoked within the last 12 months.

ALCOHOLIC was defined as current alcohol (as per the NIH cutoffs56 presented below) or recreational drug use (for both, based on medical records review and self-report without any 
prospective recording); women drinking more than 3 drinks at one time or more than 7 standard drinks a week or men drinking more than 4 drinks at one time or more than 14 standard drinks a week will be excluded. A standard drink is defined as one can or bottle of beer ( $12 \mathrm{fl} \mathrm{oz}$ ), one glass of wine ( $5 \mathrm{fl} \mathrm{oz}$ ), or one mixed drink containing $1.5 \mathrm{fl} \mathrm{oz}$ of hard liquor.

Patients were asked about the duration of symptoms like cough, breathlessness, amount, nature and diurnal variation of expectoration and severity of breathlessness to clinically categorized them into predominant chronic bronchitis and predominant emphysema. Patients had history of cough with expectoration for greater than 3 month?s duration in two consecutive years, with absent or minimal breathlessness was considered to have predominant bronchitis. Patient with history of progressive exertional dyspnoea of long duration with minimal cough which is productive of small quantity of mucoid expectoration were considered to have predominant emphysema. Patients were also asked about history of pedal edema, puffiness of face, right hypochondrial region to know whether the patients had developed right ventricular dysfunction. Patients were asked about history suggestive of bronchial asthma, tuberculosis. bronchiectasis, history of rheumatic heart disease, congenital heart disease, ischemic heart disease, history of hypertension to exclude them from the present study.

STUDY RESULTS: The present study entitled "Study of Cardiovascular morbidity \& mortality in Stable COPD on the basis of established cardiovascular risk factors." was conducted in the Department of Pulmonology, Mediciti Hospitals, and Hyderabad.

Total number of patients studied (n): 100

Total no of controls - 20

The study groups 1 - 5 were comparable as the variability between age, sex \& BMI was not significant and the study population was selected from the same ethnic community.

The following are our observations on analyzing the results of the study:-

DEMOGRAPHY OF THE STUDY:

\begin{tabular}{|l|l|l|}
\hline GOLD STAGE & MALE & FEMALE \\
\hline 1 & 10 & 5 \\
\hline 2 & 32 & 9 \\
\hline 3 & 27 & 4 \\
\hline 4 & 11 & 2 \\
\hline
\end{tabular}

The study comprised of $80 \%$ males \& $20 \%$ females with the majority of the study population formed the GOLD STAGE 2 COPD patients which were nearly $41.5 \%$ of the total study group.

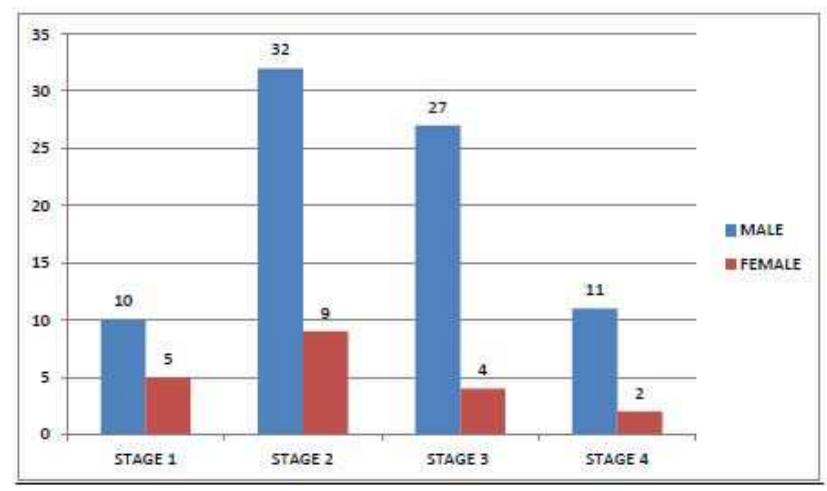




Age Distribution
\begin{tabular}{|l|l|l|}
\hline AGE & MALE & FEMALE \\
\hline $50-60$ & 29 & 4 \\
\hline $61-70$ & 22 & 10 \\
\hline $71-80$ & 29 & 6 \\
\hline
\end{tabular}

Nearly all of the patients were above 50 yrs of age with all post menopausal females. Average age of male subjects $-66.84 \pm 7.40 \mathrm{yrs}$ Average age of female subjects $-68.19 \pm 5.40 \mathrm{yrs}$
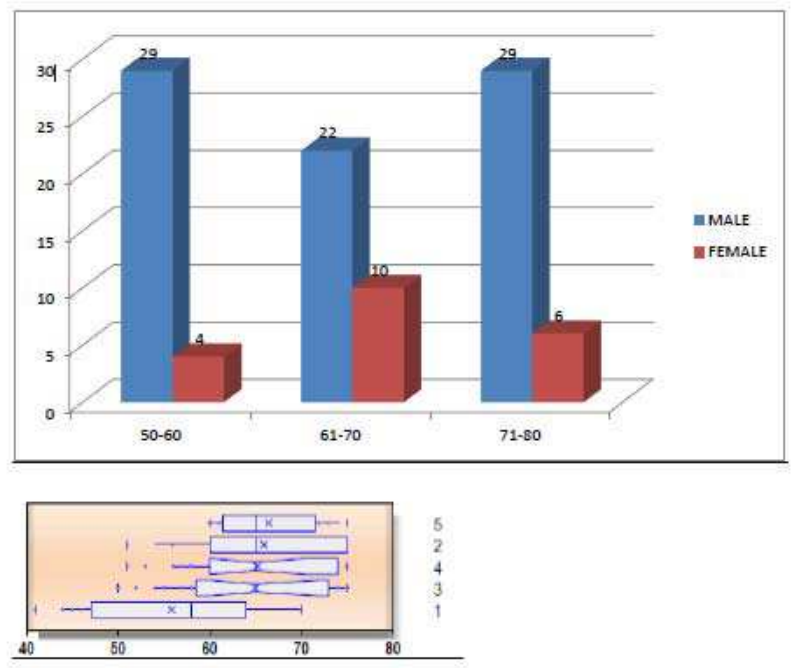

ANOVA analysis revealed homogeneity of age in the study groups and demonstrated a statistically significant relationship between increasing age and increased cardiovascular morbidity.[p < 0.05].

BMI DISTRIBUTION

\begin{tabular}{|l|l|l|}
\hline GOLD Stage & Male & Female \\
\hline 1 & 31.14 & 31.55 \\
\hline 2 & 26.72 & 26.42 \\
\hline 3 & 24.16 & 28.28 \\
\hline 4 & 20.116 & 25.15 \\
\hline
\end{tabular}

BMI distribution was homogenous amongst all the four groups with an average BMI of $25.34 \pm 6.7$ in males \& $27.85 \pm 9.2$ in female's .The BMI was found to be gradually decreasing as per increasing severity of the COPD.

Average weight of male subjects $-64 \pm 25.75 \mathrm{~kg}$, Average weight of female subjects $60.75 \pm 20.12 \mathrm{~kg}$. Average height of male subjects $-1.62 \pm 0.4 \mathrm{~m}$, Average height of female subjects $-1.560 \pm 0.3 \mathrm{~m}$. The study group comprised of 101 individuals [ female and males , mean age of yrs ,BMI $\mathrm{kg} / \mathrm{m} 2$ ] The waist \& height of the study population was $34.091 \pm 5.2689$ inches, $1.6 \pm 0.09 \mathrm{~m}$ respectively with the maximum waist size being 53 inches.The 
maximum weight of the study group was $112 \mathrm{~kg}$ with a mean of $68.615 \pm 17.8 \mathrm{~kg}$.

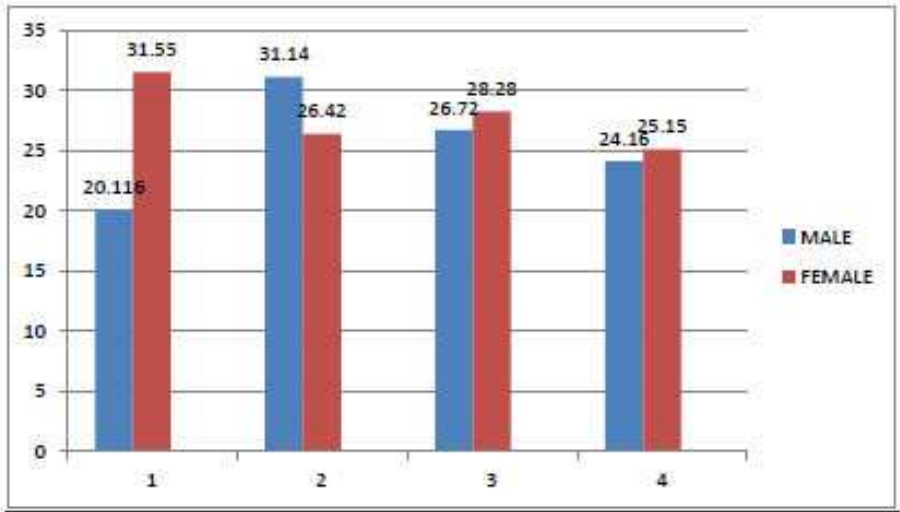

ANOVA analysis demonstrated a statistically significant correlation between BMI \& Cardiovascualr mortality

RELATION OF OBESITY TO CARDIOVASCULAR MORTALITY \& MORBIDITY: The odds ratio for the morbidity of cardiovascular disease was 1.365 [0.5825 -3.5301] with a p value $=0.5199$ while the odds ratio for the mortality of cardiovascular diseases is 0.5833 [0.2198 - 1.5483] with a p value $=0.2791$. hence no significant relation in COPD patients could be demonstrated between obese \& non obese stable COPD patients though it could be determined that with increasing severity COPD patients usually have lower BMI.

\begin{tabular}{|l|r|r|}
\hline CVD & & \\
\hline Morbidity & 15.8039 & 22.1726 \\
\hline CVD & & \\
\hline Mortality & 32.35325 & 49.37391 \\
\hline
\end{tabular}

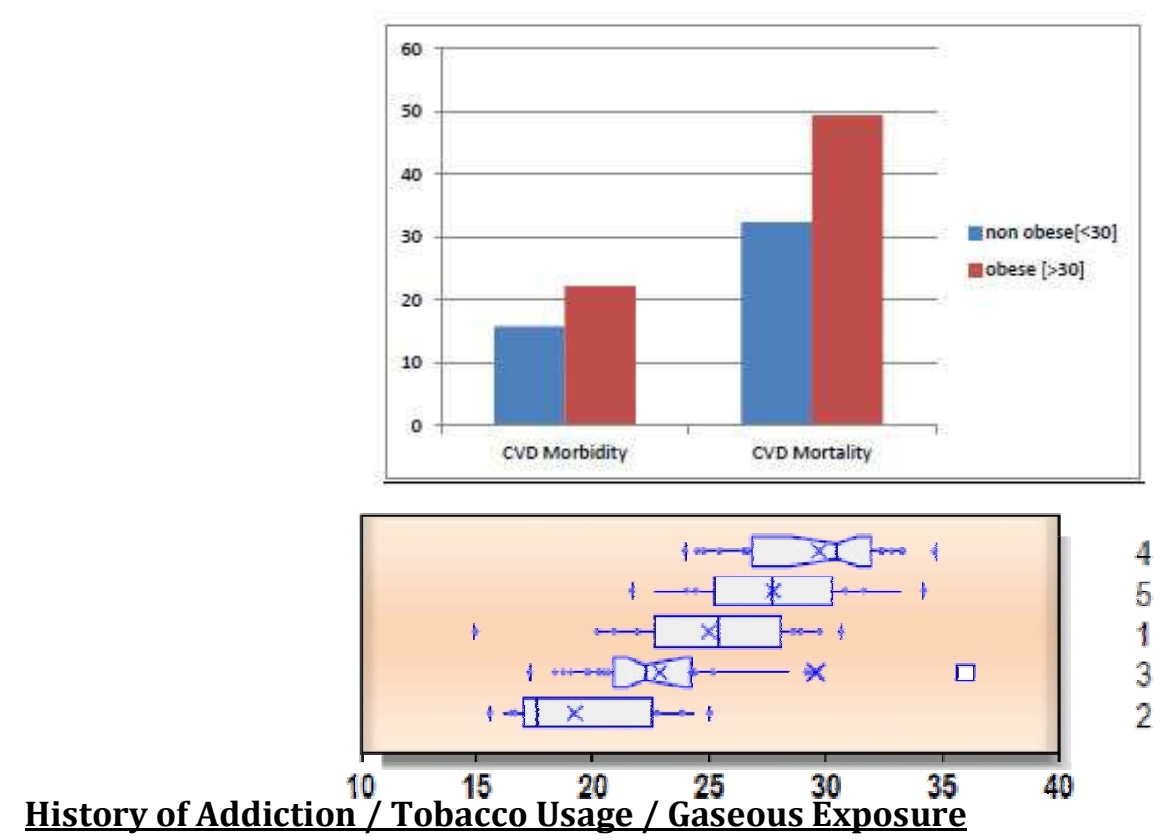




\begin{tabular}{|l|l|l|l|}
\hline & Males & Females & Quantification \\
\hline Alcoholics & 14 & & \\
\hline Current smoker & 70 & & 24.9 pack years \\
\hline Quit then started & 10 & & \\
\hline Chronic ex Old smoker & 40 & & \\
\hline Bidi smoker & 40 & & SI 1365 \\
\hline Chulha gas exposure & - & 6 & \\
\hline
\end{tabular}

History of addiction was found predominantly in males .Tobacco Smoking \& alcoholism were the major identifiable type of abuse substances., with incidence of smoking $70 \%$ with $57 \%$ using bidi with an average Smoking index of 1365 \& cigarette smokers with an average of 24.9 pack years

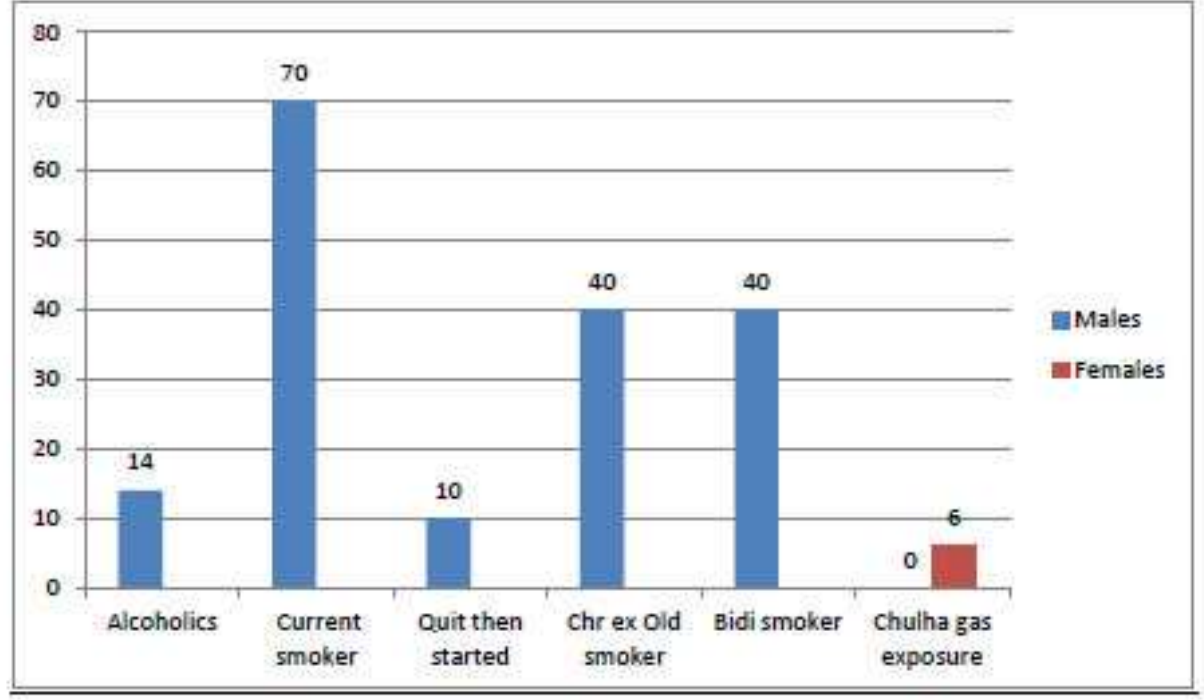

Statistical Significance Could Be demonstrated into the Cardiovascular Morbidity \& Mortality \& Smoking History by the ANOVA analysis [ $\mathrm{p}<0.05]$

\section{Correlation to Smoking \& CVD risk}

\begin{tabular}{|l|l|l|}
\hline Duration of smoking & CVS MORTALITY & CVS MORBIDITY \\
\hline 10 & $\mathbf{1 0 . 1}$ & $\mathbf{2 1 . 5 5}$ \\
\hline 20 & $\mathbf{1 8 . 1 4}$ & $\mathbf{2 0 . 4 2}$ \\
\hline 30 & $\mathbf{2 6 . 7 2}$ & $\mathbf{2 0 . 2 8}$ \\
\hline 30 pack yrs & $\mathbf{3 3 . 1 6}$ & $\mathbf{2 8 . 1 5}$ \\
\hline Non Smokers & 5.6 & 6.7 \\
\hline
\end{tabular}

A statistically significant relationship is demonstrated between the duration of smoking \& the incidence of cardiovascular mortality \& morbidity. 


\section{ORIGINAL ARTICLE}

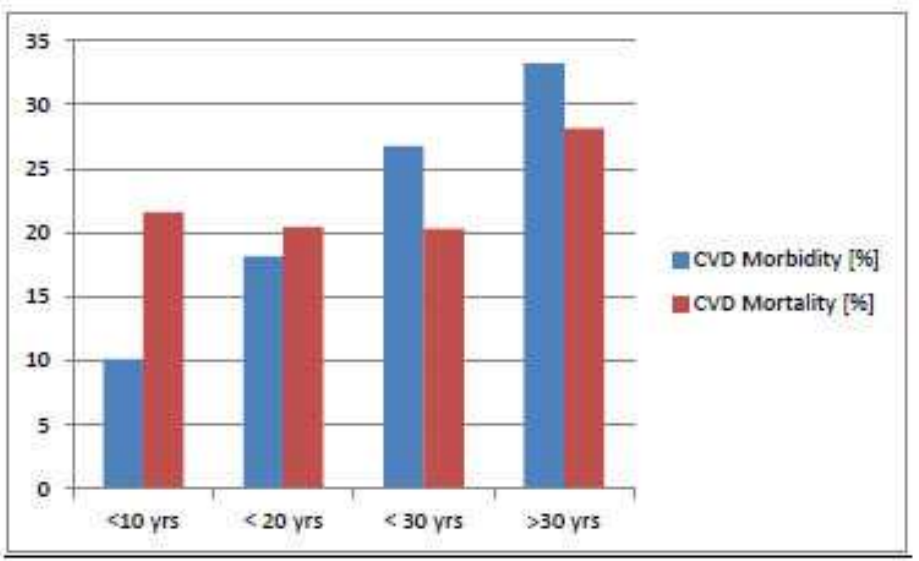

ANOVA trend analysis failed to show any significant difference in the smoking status on comparison of the various study groups.

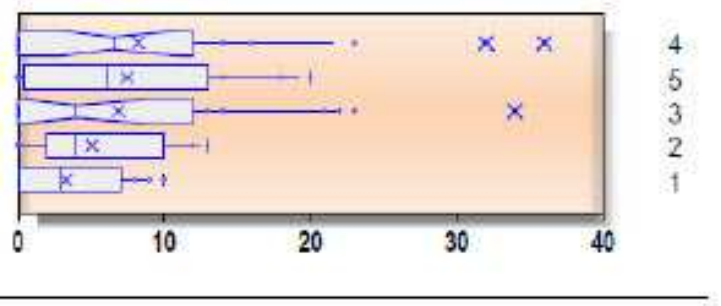

On intergroup analysis with the DUNNET test significant variation was found between the Groups $3 \& 4$ and the control group.

On intergroup analysis with the DUNNET test significant variation was found between the Groups $3 \& 4$ and the control group.

\section{Systemic Hypertension}

\begin{tabular}{|l|l|l|}
\hline GOLD STAGE & MALE & FEMALE \\
\hline $\mathbf{1}$ & 7 & 1 \\
\hline $\mathbf{2}$ & 15 & 7 \\
\hline $\mathbf{3}$ & 16 & 4 \\
\hline $\mathbf{4}$ & 4 & 2 \\
\hline
\end{tabular}

$70 \%$ of the female stable copd patients were hypertensives with females in both gold stage $3 \& 4$ having $100 \%$ incidence of systemic hypertension as compared to $52.5 \%$ of the male patients. 

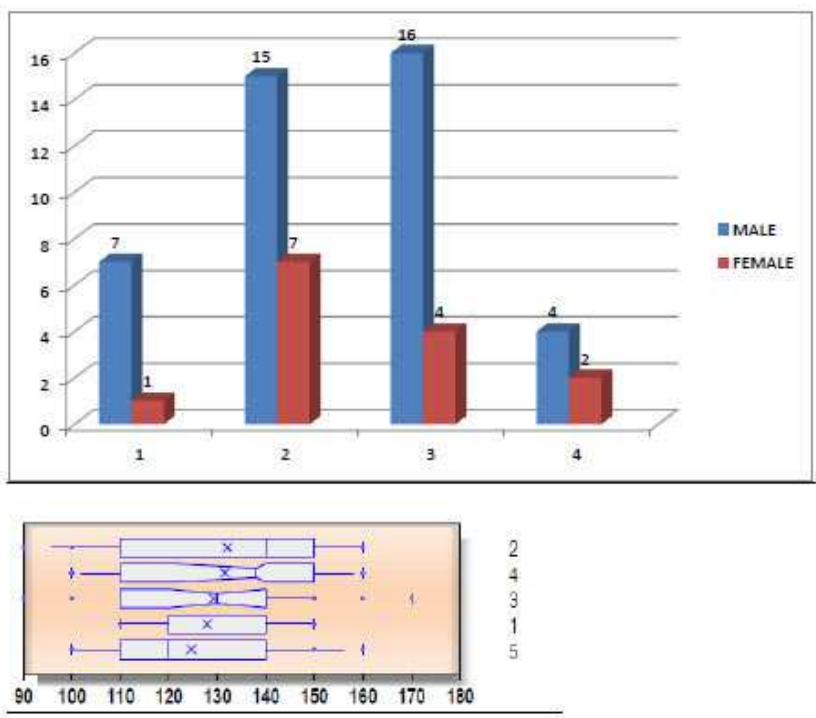

Distribution analysis of the study variable revealed a homogenous distribution between all

the study groups and no statistical significance correlation to CVD risk could be

demonstrated.

\section{CRP DISTRIBUTION}

\begin{tabular}{|l|l|l|l|l|l|}
\hline GOLD STAGE & $\mathbf{1}$ & $\mathbf{2}$ & $\mathbf{3}$ & $\mathbf{4}$ & CTRL \\
\hline MALE & 18.42 & 20.14 & 29.44 & 66.5 & 7.01 \\
\hline FEMALE & 15.69 & 13.08 & 30.74 & 83.00 & 6.89 \\
\hline
\end{tabular}

An average of $83.00 \& 66.5 \mathrm{mg} \%$ was found in GOLD STAGE 4 males \& females respectively as compared to an average of $28.63 \pm 25.1 \mathrm{mg} \%$ in the study population.

ANOVA analysis \& Dunnet test applied on the study population revealed a statistically significant \& positive correlation between Serum CRP levels number of cardiovascular risk
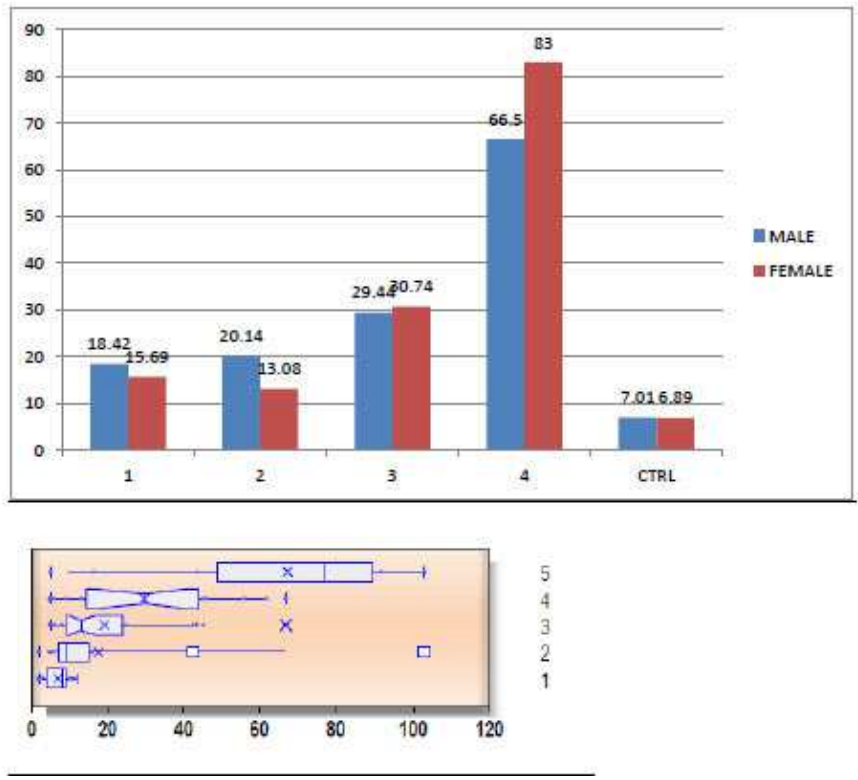

ANOVA analysis demonstrated a statistical significant difference in the values over the various 
stages of COPD and an intergroup significant variation could be demonstrated between stage $3 \&$ 4 with various stage of COPD.

\section{Co morbidities In The Stable COPD Patients}

\begin{tabular}{|l|l|l|}
\hline Co morbidity & Males & Females \\
\hline Systemic & 42 & 14 \\
\hline hypertension & & \\
\hline Rheumatoid & 0 & 8 \\
\hline arthritis & & \\
\hline Acid peptic & 35 & 25 \\
\hline disease & & \\
\hline Depression & 1 & 5 \\
\hline Chronic kidney & 8 & 9 \\
\hline disease & & \\
\hline Benign & 40 & \\
\hline prostatic & & \\
\hline hypertrophy & & \\
\hline T 2 Diabetes & 42 & 12 \\
\hline Mellitus & & \\
\hline
\end{tabular}

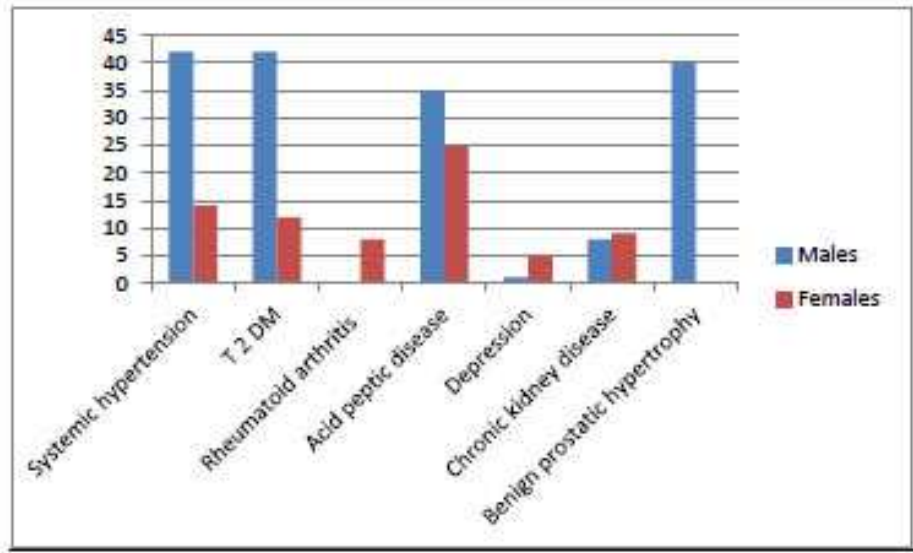

On an analysis of various risk medical co morbidities observed in the stable COPD group of patients. Several medical co morbidities were observed which were usually common in this age group but are not documented risk factors for cardiovascular mortality or morbidity .In the male subset BPH \& APD were documented in high frequency while in the female subset a higher incidence of depression \& RA was observed.

Diabetes Mellitus Type 2 Distributions

\begin{tabular}{|l|l|l|l|l|}
\hline GOLD STAGE & $\mathbf{2}$ & $\mathbf{3}$ & $\mathbf{4}$ \\
\hline Male & 7 & 18 & 13 & 4 \\
\hline Female & 4 & 5 & 1 & 2 \\
\hline
\end{tabular}

An average incidence of $44 \%$ was observed in the study population with the highest incidence being identified in the GOLD STAGE 4 female COPD subset [100\%] \& GOLD STAGE 1 male COPD subset [70\%].

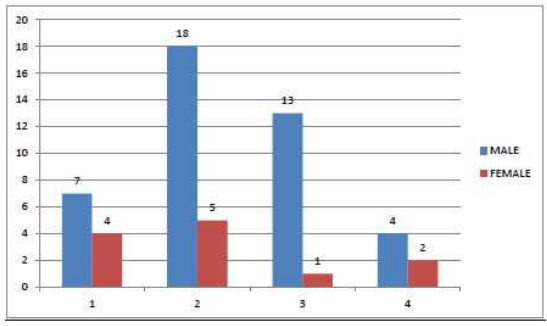

ANOVA demonstrated an homogenous distribution of COPD and comparable incidence in the study groups and hence was unable to demonstrate an statistically significant in the incidence,

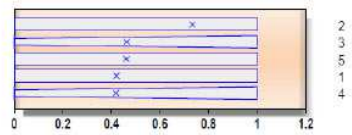

Of type 2 DM \& Cardiovascular morbidity in COPD patients. 


\section{D Echocardiography}

\section{D ECHO FINDING MALES FEMALE}

\begin{tabular}{|l|l|l|}
\hline Left Ventricular Hypertrophy & 40 & 9 \\
\hline LV Dysfunction & 15 & 2 \\
\hline RV Dysfunction & & \\
\hline Cor Pulmonale [RA,RV DILATION] & & \\
\hline Mild & 26 & 8 \\
\hline Moderate & 17 & 1 \\
\hline Severe & 16 & 2 \\
\hline Valvular heart disease & 2 & 5 \\
\hline Pulmonary hypertension & 33 & 10 \\
\hline Pericardial disease & 1 & - \\
\hline
\end{tabular}

The most common 2 D ECHO abnormalities in males were LVH [50\%], Cor Pulmonale [59\%] $\&$ in females was Cor Pulmonale [55\%]

\section{Electrocardiographic Findings}

\begin{tabular}{|l|l|l|}
\hline EKG & MALES [\%] & FEMALES [\%] \\
\hline Normal sinus rhythm & 59 & 70 \\
\hline Sinus tachycardia & 40 & 30 \\
\hline Sinus bradycardia & 1 & - \\
\hline Arrhythmias & 5 & 6 \\
\hline LBBB & 2 & 1 \\
\hline RBBB & 2 & 5 \\
\hline Left axis deviation & 24 & 20 \\
\hline Right axis deviation & 25 & 28 \\
\hline
\end{tabular}

The electrocardiogram revealed normal sinus rhythm in majority of the study group [59\% in males \& $70 \%$ in females] followed by sinus tachycardia.

Left Ventricular Hypertrophy Distribution

\begin{tabular}{|l|l|l|l|l|}
\hline GOLD STAGE & $\mathbf{1}$ & $\mathbf{2}$ & $\mathbf{3}$ & $\mathbf{4}$ \\
\hline Male & 5 & 15 & 14 & 6 \\
\hline Female & 2 & 5 & 1 & 1 \\
\hline
\end{tabular}

High incidence of Left ventricular hypertrophy was seen in GOLD STAGE 4 COPD patients [54.5\% in males \& 50\% in females] \& GOLD STAGE 2 females [55.5\%] with an average incidence of $49 \%$. 


\section{ORIGINAL ARTICLE}
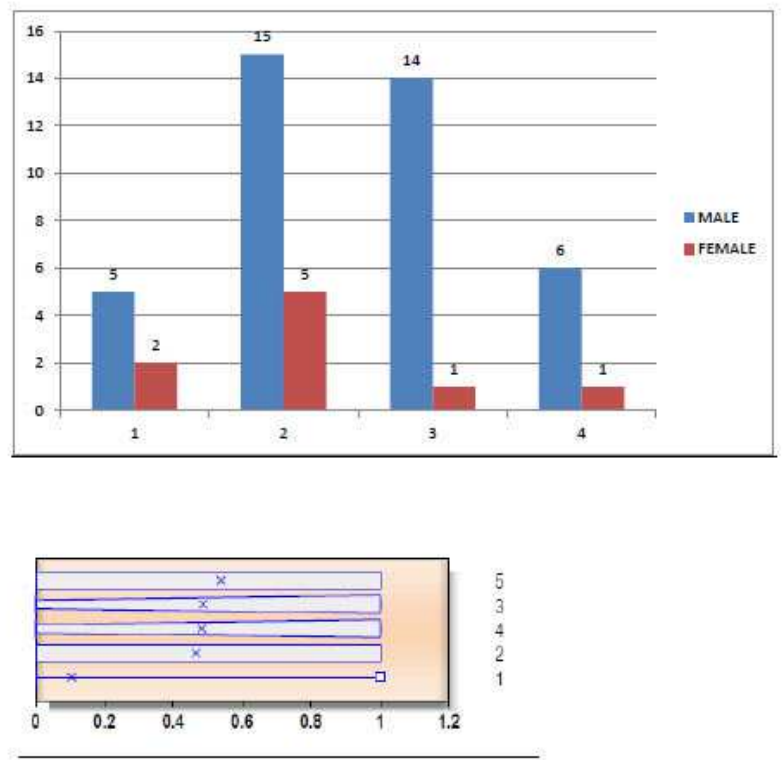

A statistically significant trend in between increasing severity of COPD \& LVH was demonstrable by the ANOVA test $[\mathrm{p}<0.05]$.

\section{Family history}

\begin{tabular}{|l|l|l|}
\hline Family history & Males & Female \\
\hline Yes & 42 & 10 \\
\hline No & 38 & 10 \\
\hline
\end{tabular}

A positive family history of cardiovascular diseases amongst first degree relatives was elicited in $50 \%$ of the female subject population \& $51 \%$ of the male COPD subset.
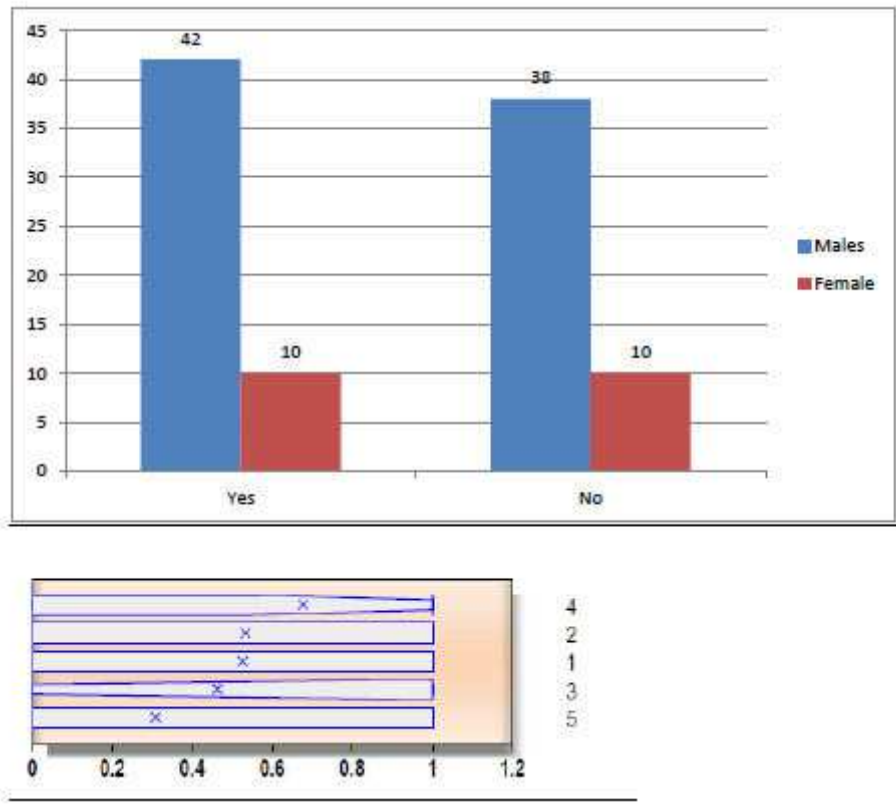

A uniform distribution of positive family history was demonstrated between all the study groups 
and control group hence no statistical significance could be demonstrated to the incidence of cardiovascular risk factors \& COPD.

\section{Lipid Profile}

\begin{tabular}{|c|c|c|c|c|}
\hline $\begin{array}{l}\text { GOLD STAGE OF COPD } \\
\text { [FEMALE] }\end{array}$ & \begin{tabular}{|l|} 
TOTAL \\
CHOLESTEROL[mg/dl]
\end{tabular} & $\begin{array}{l}\text { LDL } \\
{[\mathrm{mg} / \mathrm{dl}]}\end{array}$ & $\begin{array}{l}\text { HDL } \\
{[\mathrm{mg} / \mathrm{dl}]}\end{array}$ & $\begin{array}{l}\text { TG } \\
{[\mathrm{mg} / \mathrm{dl}]}\end{array}$ \\
\hline 1 & \begin{tabular}{|l|}
162 \\
\end{tabular} & 87 & 42.83 & 102.8 \\
\hline 2 & 176.88 & 100.22 & 47.11 & 79.11 \\
\hline 3 & 201 & 137.25 & 35.5 & 88.25 \\
\hline 4 & 157.5 & 73.5 & 57 & 72 \\
\hline $\begin{array}{l}\text { GOLD STAGE OF COPD } \\
\text { [MALE] }\end{array}$ & $\begin{array}{l}\text { TOTAL CHOLESTEROL } \\
{[\mathrm{mg} / \mathrm{dl}]}\end{array}$ & $\begin{array}{l}\text { LDL } \\
{[\mathrm{mg} / \mathrm{dl}]}\end{array}$ & $\begin{array}{l}\text { HDL } \\
{[\mathrm{mg} / \mathrm{dl}]}\end{array}$ & $\begin{array}{l}\text { TG } \\
{[\mathrm{mg} / \mathrm{dl}]}\end{array}$ \\
\hline 1 & \begin{tabular}{|l|l}
154.88 \\
\end{tabular} & 84.22 & 39.66 & 82.11 \\
\hline 2 & 168.75 & 95.06 & 39.06 & 93.15 \\
\hline 3 & 162.74 & 84.59 & 41.59 & 82.22 \\
\hline 4 & 162.54 & 90.81 & 42.818 & 101.25 \\
\hline
\end{tabular}

Fasting lipid profile of COPD group was studied which revealed deranged lipid profile parameters in the GOLD STAGE 3 female \& GOLD STAGE 4 male subgroups only .

The average total cholesterol in the female group was $174.35 \pm 19.60$ as compared to $111.15 \pm$ $5.68 \mathrm{mg} / \mathrm{dl}$ in the male study population. Highest total cholesterol was reported in GOLD STAGE 3 female COPD subset of $201.00 \mathrm{mg} / \mathrm{dl}$.

The average LDL, HDL \& TG in the female group were $78.44 \pm 27.733,71.96 \pm 9,96.5578 \pm 13.29$ $\mathrm{mg} / \mathrm{dl}$ respectively. The corresponding variables in the male group were $88.67 \pm 5.223,40.782 \pm$ $1.73 \& 83.674 \pm 9.28 \mathrm{mg} / \mathrm{dl}$ respectively.
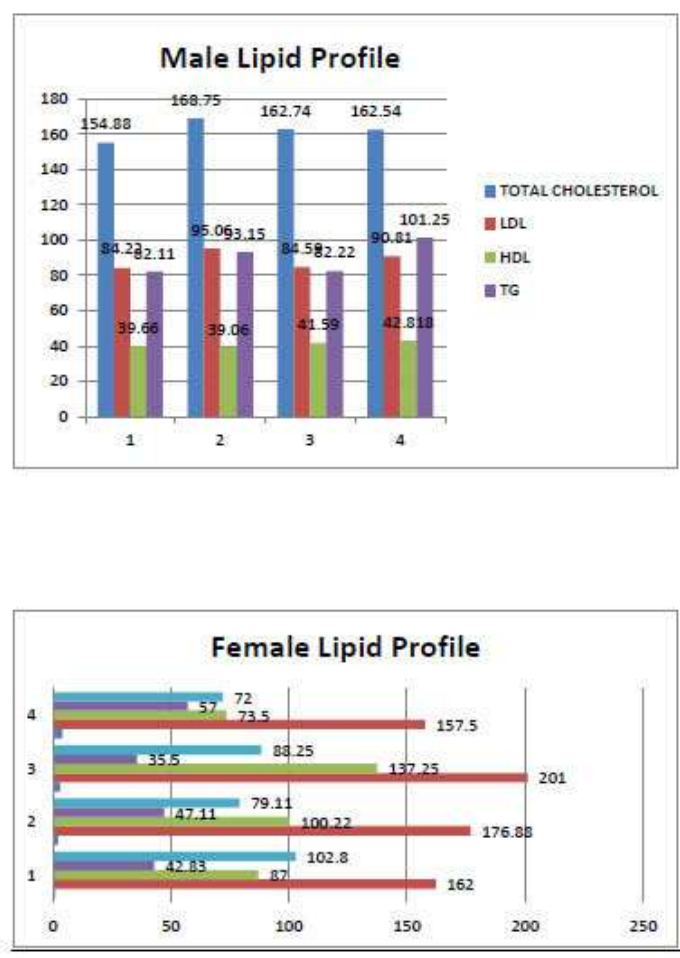


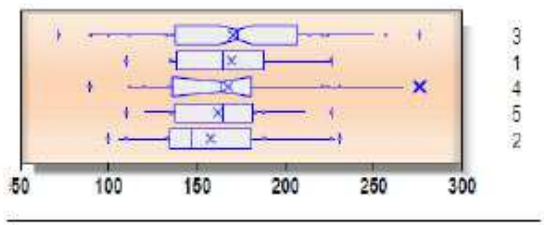

\section{ANOVA for HDLCIma/dll}

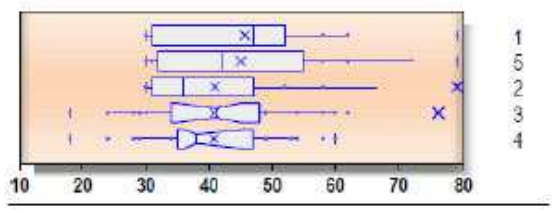

A uniform distribution of LIPID PROFILE variables was demonstrated between all the study groups and control group hence no statistical significance could be demonstrated to the incidence of cardiovascular risk factors \& COPD.

\section{Treatment related cardiovascular mortality \& morbidity}

\begin{tabular}{|l|l|r|r|r|r|r|}
\hline Treatment codes & Treatment & $\mathrm{N}$ & Morbidity & value & Mortality & p value \\
\hline 1.Inhaled & $\mathbf{1}$ & 5 & & 0.54 & & 0.41 \\
\hline Anticholinergics & & & 29.96 & & 9.313333 & \\
\hline 2. LABA & $\mathbf{1 + 2}$ & 15 & 15.61897 & 0.38 & 10.32759 & 0.30 \\
\hline 3. ICS & $\mathbf{1 + 2 + 3}$ & 56 & 27.5 & 0.16 & 12.375 & 0.28 \\
\hline 4. ORAL & $\mathbf{1 + 2 + 3 + 4}$ & 70 & & 0.67 & & $<0.001$ \\
\hline BRONCHODILATOR & & & 42.78108 & & 16.85405 & \\
\hline 5. ORAL STEROIDS & $\mathbf{1 + 2 + 3 + 4 + 5}$ & 47 & 47.5875 & $<0.001$ & 21.0125 & $<0.001$ \\
\hline 6. H.O.T & $\mathbf{1 + 2 + 3 + 4 + 5 + 6}$ & 7 & 48.63333 & $<0.0001$ & 19.43333 & $<0.0001$ \\
\hline 7. HMG Co A & $\mathbf{7}$ & 20 & & & & \\
\hline Reductase inhibitors & & & & & & \\
\hline & & & 28.180 & 0.69 & 26.85405 & 0.39 \\
\hline
\end{tabular}

The analysis of the COPD patients and its correlation to the treatment being taken by Them reveal that a statistically significant relation to mortality \& morbidity [ $\mathrm{p}<0.0001]$ is demonstrated in patients on oral steroids \& Home oxygen therapy. No, significant association to mortality \& morbidity was demonstrable between other established treatment modalities.

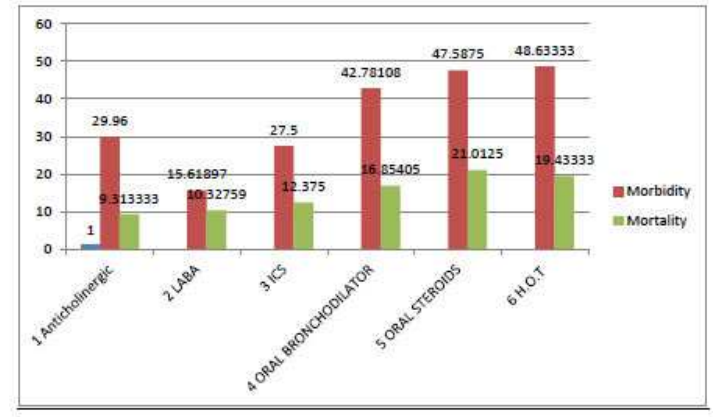




\section{$\underline{\text { Stage Wise Distribution of CVD, MI, CVD Mortality \& Se CRP Levels }}$}

\begin{tabular}{|l|r|r|r|r|}
\hline & \multicolumn{1}{|l|}{ STAGE } & \multicolumn{1}{l|}{ STAGE } & \multicolumn{1}{l|}{ STAGE } & \multicolumn{1}{l|}{ STAGE } \\
\hline Column1 & $\mathbf{1}$ & $\mathbf{2}$ & $\mathbf{3}$ & $\mathbf{4}$ \\
\hline MORBIDITY[\%] & 35.19 & 33.85 & 38.84 & 38.48 \\
\hline MORTALITY[\%] & 14.12 & 13.77 & 13.47 & 14.88 \\
\hline CRP [meq/L] & 17.51 & 19.21 & 29.73 & 67.46 \\
\hline
\end{tabular}

The incidence of cardiovascular diseases was $36.59 \%$ in all GOLD STAGEs as compared to $16.32 \%$ in the control population. The highest cardiovascular risk for developing cardiovascular diseases in male study population was recorded in GOLD STAGE 1 of $41.9 \%$ as compared to GOLD STAGE 4 females with a CVD risk of 53.7\%.

The risk of myocardial infarction was nearly three times in the stable COPD patients $15.045 \%$ as compared to $5.08 \%$ in the study group with the highest risk of $19.64 \%$ in the GOLD STAGE 1 males and $16.12 \%$ in GOLD STAGE 2 females.

The risk of cardiovascular mortality was $14.06 \%$ in the COPD patients [ as compared to $3.168 \%$ :control population].Males with COPD GOLD STAGE 1 were excessively predisposed with a mortality risk of $14.12 \%$ as compared to a risk of $23.10 \%$ in GOLD STAGE 4 females .

Nearly fivefold elevations of Serum CRP levels were found in the COPD group of patients as compared to the control population nearly 12 times elevation being recorded in the GOLD STAGE 4 COPD study population [males $-67.46 \&$ females $-66.4 \%$ ]

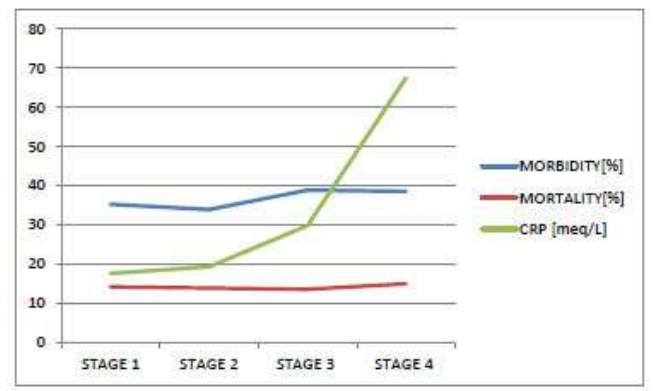

ANOVA FOR CARDIOVASCULAR DISEASE MORBIDITY

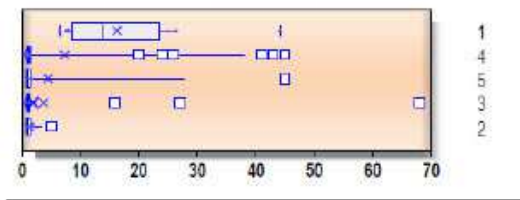

\section{ANOVA FOR CARDIOVASCULAR DISEASE MORTALITY}

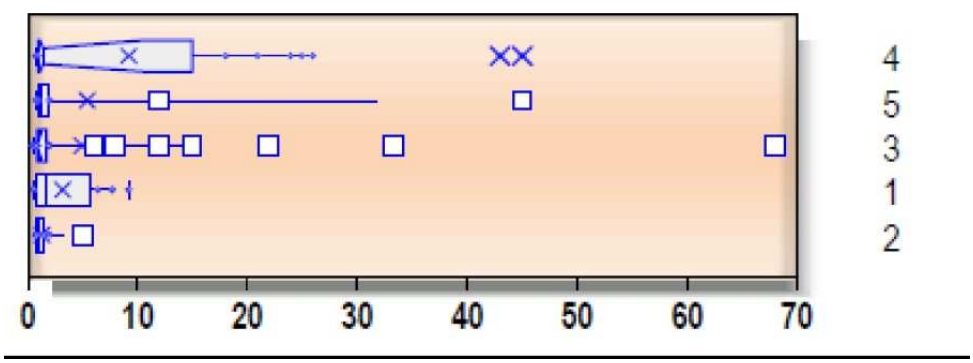


Progressive trend analysis of the study population revealed a statistically significant association in between the increasing severity of COPD \& the estimated cardiovascular morbidity risk[ $\mathrm{p}<$ 0.05 ] but a similar statistical association could not be demonstrated for incidence of cardiovascular mortality \& the risk of myocardial infarction.

\section{Relative Risk of Cardiovascular Morbidity in COPD}

\begin{tabular}{|l|l|l|}
\hline STAGE & MALE & FEMALE \\
\hline 1 & 1.2 & 1.2 \\
\hline 2 & 1.0625 & 0.44 \\
\hline 3 & 1.11 & 1 \\
\hline 4 & 1.0909 & 1 \\
\hline
\end{tabular}

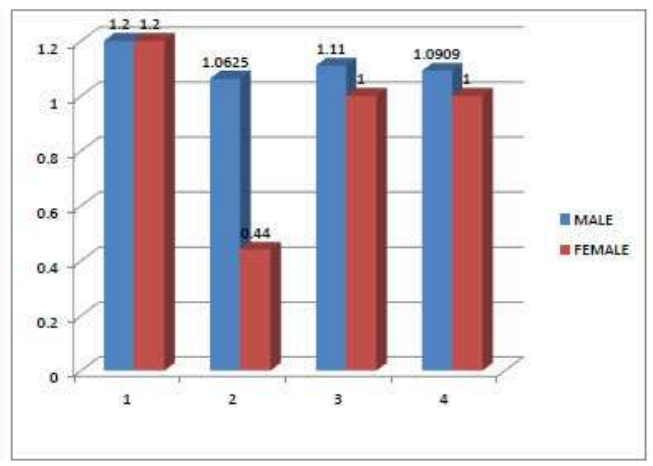

Relative Risk of Cardiovascular Morbidity

Relative Risk of Cardiovascular Morbidity

\begin{tabular}{|l|l|l|}
\hline GOLD STAGE & MALE & FEMALE \\
\hline & & \\
\hline 1 & 1.2 & 1.2 \\
\hline 2 & 1.0625 & 0.44 \\
\hline 3 & 1.111 & 1 \\
\hline 4 & 1.0909 & 1.00 \\
\hline
\end{tabular}

The relative risk of cardiovascular morbidity was observed in the various GOLD stages with the highest risk observed in the STAGE 1 Male \& female subgroups [ RR 1.2 , p $0.0023 \mathrm{f} 0.01$ ].Statistically significant risks of morbidity as compared to the control group was observed in GOLD stage $3 \& 4$ [ $\mathrm{p}<0.0001$ respectively ] .

ANOVA analysis determines a statistically significant association between increasing severity of Stage of COPD and Cardiovascular morbidity.

\section{RELATIVE RISK OF CARDIOVASCULAR MORTALITY IN COPD}

\begin{tabular}{|r|r|r|}
\hline STAGE & \multicolumn{1}{l|}{ MALE } & FEMALE \\
\hline 1 & 1 & 0.64 \\
\hline 2 & 0.875 & 0.356 \\
\hline 3 & 1.11 & 0.8 \\
\hline 4 & 1.0909 & 0.8 \\
\hline
\end{tabular}




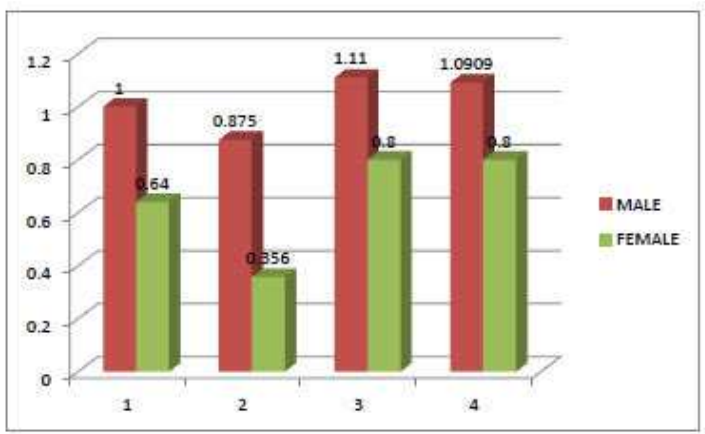

RELATIVE RISK OF CARDIOVASCULAR MORTALITY

\begin{tabular}{|l|l|l|}
\hline GOLD STAGE & MALE & FEMALE \\
\hline 1 & 1.0 & 0.64 \\
\hline 2 & 0.8750 & 0.356 \\
\hline 3 & 1.111 & 0.800 \\
\hline 4 & 1.0909 & 0.800 \\
\hline
\end{tabular}

CVS mortality over a period of ten years was evaluated and demonstrated to be higher in all GOLD STAGES particularly in STAGE 1, 3\& 4. Statistically significant differences were observed in all male subsets of the study \& in female stage $3 \& 4$. ANOVA above mentioned subset failed to reveal a statistically significant association in between the increasing severity of COPD \& Cardiovascular mortality.

On comparison of individual groups using the Dunnet test, statistically significant and higher mortality could be demonstrated in between stages $3 \& 4$. The CVS mortality was comparable in between the control and stage $1 \& 2$ COPD patients.

\section{INCIDENCE OF MYOCARDIAL INFARCTION IN COPD}

\begin{tabular}{|r|r|r|}
\hline STAGE & MALE & FEMALE \\
\hline 1 & 0.96 & 2.4 \\
\hline 2 & 1.95 & 0.89 \\
\hline 3 & 1.422 & 1 \\
\hline 4 & 1.3091 & 1 \\
\hline
\end{tabular}

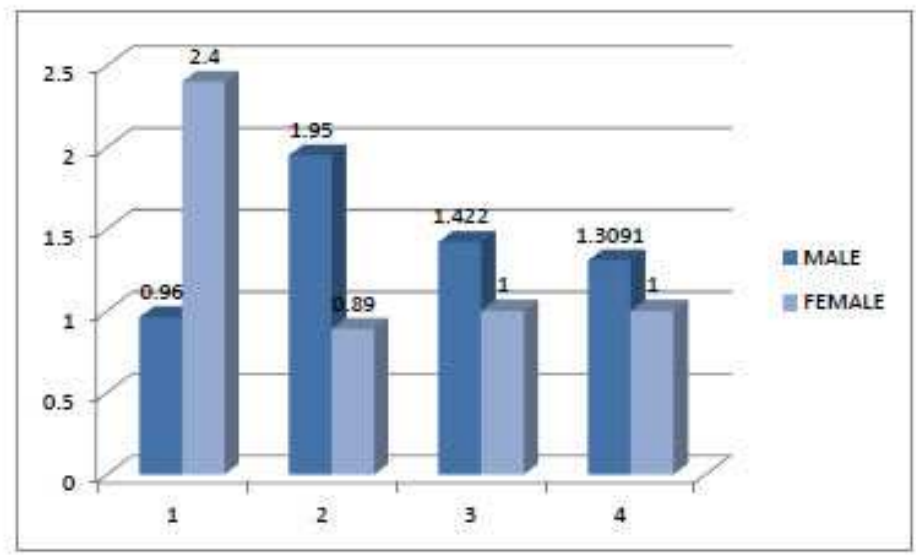

The relative risk of incurring a myocardial infarction was highest in the GOLD STAGE $3 \& 4 \&$ 
female population in stage 1 COPD though ANOVA analysis or the DUNHILL test failed to show any statistically significant association in between the various groups.

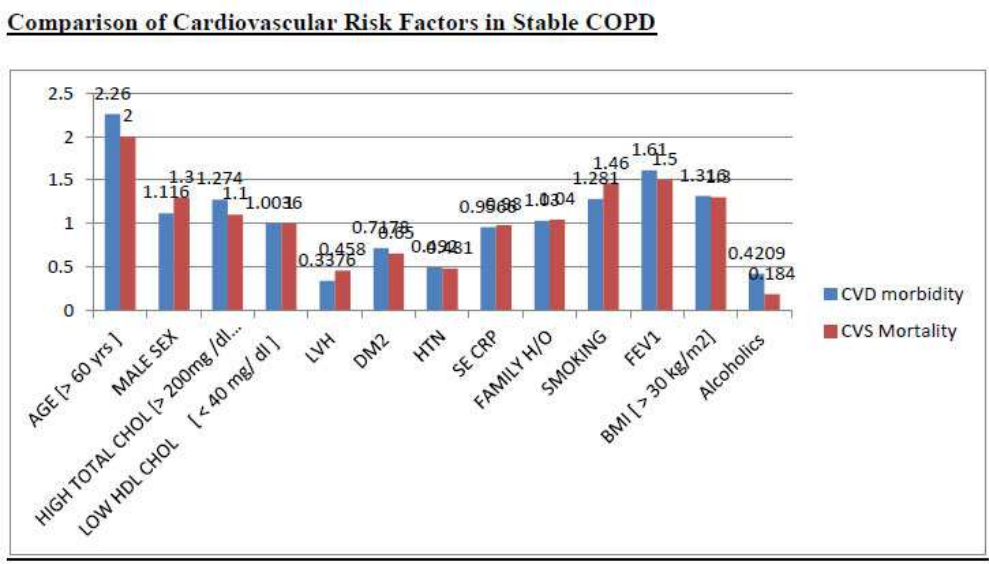

\begin{tabular}{|l||l|l|}
\hline RISK FACTORS & CVD morbidity & CVS Mortality \\
\hline Age & 2.26 & 2.00 \\
\hline Male Sex & 1.116 & 1.3 \\
\hline HIGH TOTAL CHOL [>200mg /dl ] & 1.274 & 1.1 \\
\hline LOW HDL CHOL $[<\mathbf{4 0} \mathbf{~} \mathbf{~ g / ~ d l ~ ] ~}$ & 1.0036 & 1 \\
\hline LVH & 0.3376 & 0.458 \\
\hline DM2 & 0.7178 & 0.65 \\
\hline HTN & 0.4920 & 0.481 \\
\hline
\end{tabular}

\begin{tabular}{|l|l|l|}
\hline SE CRP & 0.9566 & 0.98 \\
\hline FAMILY H/0 & 1.03 & 1.04 \\
\hline SMOKING & 1.2810 & 1.46 \\
\hline FEV1 & 1.61 & 1.5 \\
\hline BMI [ > 30 & 1.316 & 1.3 \\
\hline $\mathbf{k g} / \mathbf{m} 2]$ & & \\
\hline Alcoholics & 0.4209 & 0.184 \\
\hline & & \\
\hline
\end{tabular}

With respect to cardiovascular morbidity an unpaired $t$ test revealed a statistically significant association with Age, Left ventricular hypertrophy, Systemic hypertension, Serum C Reactive protein, Smoking \& alcohol. With respect to cardiovascular mortality an unpaired t test revealed a statistically significant association with Age, Left ventricular hypertrophy, Systemic hypertension, Serum C Reactive protein, Smoking. On comparison of the various risk factors individually statistically significant association to an increased risk of cardiovascular morbidity \& mortality was seen with Left Ventricular Hypertrophy [p value $<0.0001$ ]. An increased relative risk in morbidity \& mortality was also observed in with risk factors like Age, Hypertension, Serum CRP, and LVH \& Smoking.

DISCUSSION: COPD is a leading cause of morbidity and mortality. COPD is estimated third leading cause of mortality and forth leading cause of morbidity worldwide by 2020.

In a study period of 2 years from 2007 to 2009 a point observation study of Cardiovascular Risk factors was conducted in the Dept of Pulmonology in Mediciti Hospital, Hyderabad on stable COPD patients presenting to the Pulmonology Out Patient Department.An attempt was made to analyze the risk of cardiovascular mortality and morbidity in thesepatients on the basis of 
established cardiovascular risk factors [Age, Sex, Lipid Profile etc.]An attempt was made to analyze whether these parameters correlated to the increasing severityof COPD and how much patients of COPD are predisposed to cardiovascular disease in terms ofmorbidity and mortality as compared to the control population.

A] Comparative analysis of Cardiovascular Mortality \& Morbidity : Various studies have reported a strong link between the occurrence of COPD and the presence of CAD. The causal link between these diseases has historically been cigarette smoking, but the exact mechanisms have only recently been studied. Epidemiologic evidence supports the importance of systemic inflammation in the pathogenesis of atheroma formation and ischemic heart disease, and recent studies have indicated that patients with COPD have a prominent systemic inflammatory response $(57,59-64)$.

The anatomical and functional relation that exists between the lungs and the heart is such that any dysfunction that impacts in one of the organs is likely to have consequences on the other. This may be possibly because patients with COPD tend to have higher incidence of CAD due to persistent raised systemic inflammatory status of the individual. This is the possibility in view of which patients from our study were also evaluated with CRP to further document this raised inflammation.

Relative odds of these parameters in various studies based on the results \& risk equations derived from the Framingham Cardiovascular Risk factor trial, Lung health study \& NHANES trial reveal,

\begin{tabular}{|l|l|l|}
\hline Author & CVS mortality & \\
\hline & Male & Female \\
\hline \multirow{3}{*}{ Hole[1] } & 1.56 & 1.88 \\
\cline { 2 - 3 } & & \\
\hline Schunemann[2] & $2.11[\mathrm{M}]$ & $1.96[\mathrm{~F}]$ \\
\hline Hospers[3] & $1.82[\mathrm{M}]$ & $1.10[\mathrm{~F}]$ \\
\hline Knulman[4] & $1.10[\mathrm{M}]$ & $1.07[\mathrm{~F}]$ \\
\hline Eichkoff et al[5] & $1.62[\mathrm{M}]$ & $1.70[\mathrm{~F}]$ \\
\hline Sin et al [6] & $1.26[\mathrm{M}]$ & $1.19[\mathrm{~F}]$ \\
\hline The Framingham Heart & $1.9[\mathrm{M}]$ & $1.3[\mathrm{~F}]$ \\
\hline Study [7] & & \\
\hline Present study & $\mathbf{1 . 5}[\mathrm{M}]$ & $\mathbf{1 . 4}[\mathrm{F}]$ \\
\hline & & \\
\hline
\end{tabular}

Stage wise analysis of the relative risk of cardiovascular morbidity was compared with various studies which revealed, relative risk of cardiovascular risk factors in patients $[<$ $0.01 \mathrm{p}$ value $>0.001]$.

\begin{tabular}{|l|l|l|}
\hline GOLD & D.M. & Present \\
\hline STAGE & MANNINO ET AL.[11] & study \\
\hline Control & 1 & $\mathbf{1}$ \\
\hline 1 & 2.4 & $\mathbf{1 . 2}$ \\
\hline 2 & 1.7 & $\mathbf{0 . 6 8}$ \\
\hline 3 & 2.2 & $\mathbf{1 . 3}$ \\
\hline 4 & 2.4 & $\mathbf{1 . 5}$ \\
\hline & & \\
\hline
\end{tabular}

In the lung health study, for every $10 \%$ decrease in FEV1, cardiovascular mortality increases by about $28 \%$, and nonfatal coronary event increases by about $20 \%$ in mild to moderate COPD.

B] Serum C Reactive Protein level: The present study revealed an average CRP of $28.43 \mathrm{mg} / \mathrm{dl}$ with a statistically significant increase in CRP levels over the several stages of COPD. High intergroup variability was also demonstrable between the stages $3 \& 4$ and stage 1 of COPD patients.

This may be explained by the raised neutrophils counts in the BAL of COPD patients, or recurrent infections to which the population is recurrently exposed. 
Several studies have provided convincing evidence that COPD is associated with increased levels of several proinflammatory cytokines and its soluble receptors ,interleukin 6 , C-reactive protein[CRP], oxidative stress, and activation of several inflammatory cells (e.g., neutrophils, monocytes, and lymphocytes].[7]

Stage wise comparison of the Serum CRP reveals,

\begin{tabular}{|l|l|l|l|l|l|l|l|l|}
\hline GOLD STAGE & $\mathbf{1}$ & & $\mathbf{2}$ & & $\mathbf{3}$ & & $\mathbf{4}$ & \\
\hline & Sin et & Present & Sin et & Present & Sin et & Present & Sin et & Present \\
& al [6] & & al [6] & & al [6] & & al [6] & \\
\hline & & Study & & Study & & Study & & Study \\
\hline Se CRP & 36.2 & $\mathbf{1 8 . 4 2}$ & 29.8 & $\mathbf{2 0 . 1 4} \pm$ & 45.1 & $\mathbf{2 9 . 7 3}$ & 99.9 & $\mathbf{6 6 . 5} \pm$ \\
\hline & \pm 1.8 & $\mathbf{3 . 1}$ & \pm 2.0 & $\mathbf{1 5 . 9 6}$ & \pm 1.3 & $\mathbf{1 8 . 7 7}$ & \pm 1.0 & $\mathbf{3 0 . 5}$ \\
\hline
\end{tabular}

A similar observation was made by study conducted by Sin et al which also revealed a progressively rising level of Serum CRP with the stages of COPD .It recorded an average of. $36.2 \pm$ $1.8 \mathrm{meq} / \mathrm{dl}$ in stage 1 as compared to $\mathbf{1 8 . 4 2} \pm \mathbf{3 . 1}$ in the present study in a the study conducted by Sin et al the CRP levels in stage $2, \mathbf{3}, \boldsymbol{\&} 4$ were $29.8 \pm 2.0 \mathrm{mg} / \mathrm{dl}, 45.1 \pm 1.3 \mathrm{mg} / \mathrm{dl}$ \& $99.9 \pm 1.0 \mathrm{mg} / \mathrm{dl}$ respectively while they were non significantly lower in our study $20.14 \pm$ $15.96,29.73 \pm 18.77 \& 66.5 \pm 30.5$ respectively.

C] Lung Function A study of the dynamic variables in the study population was performed \& the Comparative analysis of these parameters in various studies reveal,

\begin{tabular}{|l|l|l|}
\hline Author & Mean FEV $_{\mathbf{1}}$ (SD) Percentage of predictive & FVC $\%$ \\
\hline Hole[1] & 52 & 65 \\
\hline Schunemann[2] & 57 & 71 \\
\hline Hospers[3] & 60 & 72 \\
\hline Knulman[4] & 69 & 71 \\
\hline Sin et al [6] & 43 & 72 \\
\hline Eichkoff et al[5] & 41 & 79 \\
\hline The Framingham Heart Study [7] & 66.1 & 59.1 \\
\hline Present study & $\mathbf{6 5}$ & $\mathbf{7 2}$ \\
\hline
\end{tabular}

In the present study $85 \%(85 / 100)$ had FEV1 $<50 \%$ of the predicted i.e. is severe obstructive disease. Patients start experiencing breathlessness on any exertion when the FEV1 fall in range 80\%-50\% GOLD criteria). Thus they tend to seek medical attention during this stage and accounting for moderate to very severe obstructive defect.

Patients with mild obstructive defect that is FEV1 $>80 \%$ of predicted are usually in pre symptomatic stage and are not likely to come to medical attention, unless they develop an exacerbation of lower respiratory tract infections. This account for the fact that only $15 \%$ of the patients are in mild category in this study.

Similar to studies conducted by Sin et al \& Mannino et al a statistically significant relationship was demonstrated in between the progressively decreasing FEV1, FEV1/FVC \& risk of cardiovascular morbidity \& mortality .

This can be explained by the postulation that progressively greater airway obstruction adding to the inflammatory millue in the patient and predisposing the patient to higher risk of 
atherosclerosis and oxidant induced injury.

D] Comparison of Anthropometric Data: The study group comprised of 100 individuals [20 female and 80 males], mean age of $66.84 \pm 7.40 \mathrm{yrs}$, BMI $25.34 \pm 6.7 \mathrm{~kg} / \mathrm{m} 2$. The weight of the study population was $\mathrm{kg} \&$ an average height of .The average BMI of the individual was.

In a study conducted by Sin et al the study group consisted of 6229 individuals [ $55 \%$ males and $45 \%$ females, mean age of $67 \mathrm{yrs}$,Height of $1.66 \pm 0.07 \mathrm{~m}$,Wt of $71.5 \pm 9.29 \mathrm{~kg}$.The BMI of the group was $25 \pm 2.55 \mathrm{~kg} / \mathrm{m} 2$.

In a study conducted by The Framingham Heart Study et al included patients with mean age of 63.7 years, weight of $71.2 \mathrm{~kg}$, and height of $167.132 \mathrm{~cm}$ and body mass index of $28.4 \mathrm{~kg}$ $/ \mathrm{m} 2$.

On analysis of these variables in terms of cardiovascular risk factors revealed an almost similar trend in all the several studies with increasing BMI an increased risk of cardiovascular morbidity and mortality was reported in studies conducted by Sin et al \& Eichkoff et al .

Age $>60$ yrs was a statistically significant indicator as a predictor for cardiovascular morbidity \& mortality in studies conducted by Hole \& Schumann et al. with a relative risk of 2.36. Similar association was demonstrable but was not statistical significant in our study.

Analysis of Body mass index demonstrated a partially raised RR OF 1.316 which was statistically insignificant [ $p=0.36]$ in the present study. In the lung health study, Anthonisen et al demonstrated a relative risk of 1.07 statistically significant relationships between BMI \& cardiovascular mortality [p $<0.001]$.

C] History of Addictions: The study population was comprised of smokers predominantly $48 \%$ with only $14 \%$ alcoholics ,the smoking habits of the study group was comparable to subjects in the other study groups which demonstrated 36\% [Hole et al], 60\% [ Sin et al ]\& 56\% in an Indian population study done by Goyal et al .

Anthonisen et al [17] demonstrated that Cigarette Smoking history \& No. of pack years showed a relative risk of 1.81 times mortality \& 1.0 raised morbidity which was statistically significant with a p vale $<0.01$, in the present study we demonstrated a relative risk of 1.2810 with mortality \& 1.46 times morbidity with a p value $<0.001$.

Alcoholics had an increased relative risk of 1.01 though was statistically non significant [p 0.23.In the present study group a relative risk of 0.4209 with a $p$ value of 0.569 was demonstrated which too was statistically non significant.

B] Medical Co-Morbidities: Anthonisen et al [17] in a study demonstrated that a raised diastolic blood pressure demonstrated an elevated risk of 1.50 [mortality] \& 1.37 [morbidity] with a statistical significance of $\mathrm{p}<0.0001$.An elevated relative risk was demonstrated in the present study of 1.34 times the normotensive patient with a statistical significance of $<0.001$. Elevated Systolic blood pressure [SBP > 140] demonstrated a raised relative risk of 1.45 times as compared to our study which demonstrated an elevated risk of 1.23. The parameter was found to be statistically significant in the present study as well as the study conducted by Anthonisen et al. $[\mathrm{p}<0.01]$

Diabetes mellitus was found to have a relatively higher incidence in Stage 1[75\%] \& $4[66 \%]$ in

the present study but were found to be in highest incidence [21.8\%] in stage 3 patients in a study conducted by Sin et al. An average SBP of $139.2 \pm 2.6 \mathrm{~mm}$ of $\mathrm{Hg}$ was recorded with the present 
study with a statistically insignificant correlation to the cardiovascular morbidity \& mortality. [12]

D] Lipid Profile: Fasting lipid profiles of the study group revealed normolipidemia in the majority of cases but the higher stage of COPD patient's dyslipidemia could be identified.

Sin \& man et al in the Third Health \& Nutrition Examination Survey demonstrated that there were no significant differences in the LDL or HDL concentrations among the groups. Though participants with severe airflow obstruction had slightly lower serum concentrations of triglycerides, nothing could be demonstrated up to the level of clinical significance.

The present study demonstrated no significant correlation or difference amongst the various sub groups and lipid profile parameters ,though higher stages of COPD were associated with relatively deranged serum triglycerides \& total cholesterol.

CONCLUSIONS: The epidemiologic evidence linking COPD and cardiovascular morbidity and mortality is strong. Even after adjustments for traditional cardiovascular risk factors such as serum total cholesterol Hypertension, obesity and smoking, patients with COPD have a two- to threefold increase in the Risk of cardiovascular events including death. The following conclusions could be made from the study,

\section{REFERENCES:}

1. More severe the stage of COPD more is the risk of cardiovascular morbidity \& mortality.

2. Stable COPD patients are 1.5 [males] \& 1.4 [females] times at risk to develop cardiovascular disease as compared to the general population.

3. Among the established risk factors studied: - Age> 60 yrs, Positive Smoking, Left Ventricular Hypertrophy, and Body Mass Index $>30 \mathrm{Kg} / \mathrm{M} 2$ are found in a statistical significant correlation with progressively worsening stages of COPD.

4. A positive but statistically insignificant correlation was demonstrable between the family history of cardiovascular disease in first degree relatives of Stable COPD patients, and increasing cardiovascular morbidity \& mortality.

5. Progressively decreasing FEV1, decreasing FVC, decreasing FEV1/FVC ratio, have a statistically significant correlation to cardiovascular mortality \& morbidity.

6. Se CRP levels provide an accurate indicator for assessment of severity of cardiovascular morbidity \& mortality in Stable COPD patients.

7. Stable COPD Males have a lower BMI which explains near normal Lipid profile in the subset.

8. Significant correlations were demonstrated between the treatment that patient requires for stability \& cardiovascular disease.

9. Patients on Home Oxygen therapy, oral steroids \& bronchodilators despite being Stable COPD should be under closer surveillance for cardiovascular complications.

10. Cardiovascular disease is an important but underrated cause of COPD morbidity \& mortality Hence should be addressed to improve overall disease outcome.

11. American Thoracic Society Committee on Diagnostic Standards. Definitions and classification of chronic bronchitis, asthma and pulmonary emphysema. Am Rev Respir Dis 1962;85:762-768.

12. American Thoracic Society. Standardization of spirometry. 1994 update. Am J Respir Crit Care Med 1995; 152:1107-1136. 


\section{ORIGINAL ARTICLE}

13. American Thoracic Society. Statement. Standards for the diagnosis and care of patients with chronic obstructive pulmonary disease. Am J Respir Crit Care Med 1995; 152:S77S120 4. BTS Guidelines for the Management of Chronic Obstructive Pulmonary Disease. Thorax 1997;52(Suppl 5):S1-S28.

14. Celli BR, MacNee W; ATS/ERS Task Force. Standards for the diagnosis and treatment of patients with COPD: a summary of the ATS/ERS position paper. Eur Respir J 2004 Jun;23(6):932-946. 6.

15. Dupuis J, Larson MG, Vasan RS, et al. Genome scan of systemic biomarkers of vascular inflammation in the Framingham Heart Study: evidence for susceptibility loci on 1q.Atherosclerosis 2005; 182:307-314. 